\title{
Predictors and Clinical Impacts of Aggravated Left Ventricular Diastolic Dysfunction After Off-Pump Coronary Artery Bypass Grafting
}

\author{
Seung Hyun Lee, MD, PhD; Kwan Wook Kim, MD; Hyun-Chel Joo, MD; \\ Kyung-Jong Yoo, $\mathrm{MD}, \mathrm{PhD}$; Young-Nam Youn, $\mathrm{MD}, \mathrm{PhD}$
}

\begin{abstract}
Background: To determine the predictors of aggravated left ventricular diastolic dysfunction (LVDD) in patients undergoing off-pump coronary artery bypass grafting (OPCAB) and to compare late outcomes according to the aggravated LVDD.

Methods and Results: OPCAB was performed in 1,101 patients (2001-2013). LVDD was classified as normal, mild, moderate or severe. Patients were divided into 2 groups: non-aggravated LVDD (group I) and aggravated LVDD (group II). The primary endpoint was aggravation of LVDD. The secondary endpoint was late mortality and morbidity such as major adverse cardiac and cerebrovascular events (MACCE) related to LVDD aggravation postoperatively. There were 894 patients in group I and 207 in group II. Multivariate analysis revealed that preoperative peripheral artery obstructive disease (PAOD) $(P=0.04)$, renal failure $(P<0.01)$, and $A^{\prime}$ velocity $(P<0.01)$ anticipated aggravated LVDD. The Cox hazards model revealed that aggravated LVDD was a poor prognostic factor for MACCE $(P<0.01)$ and overall survival $(P<0.01)$. The Kaplan-Meier survival curve showed that aggravated LVDD was related to poor late outcomes (freedom from MACCE, $\mathrm{P}=0.01$; overall survival, $\mathrm{P}<0.01$ ).
\end{abstract}

Conclusions: Aggravated LVDD significantly affects late clinical outcomes after OPCAB and preoperative PAOD, renal failure, and $A^{\prime}$ velocity might be predictors. (Circ $J$ 2016; 80: 1937-1945)

Key Words: Diastolic heart failure; Doppler echocardiography; Off-pump coronary artery bypass; Peripheral arterial disease; Renal insufficiency

$\mathbf{L}$ eft ventricular diastolic dysfunction (LVDD) is related to an abnormality of diastolic distensibility, filling, and relaxation of the LV, regardless of whether the ejection fraction (EF) is normal or abnormal and whether the patient is symptomatic or asymptomatic. ${ }^{1}$ Tissue Doppler imaging (TDI), which visualizes 3 waveforms during the cardiac cycle (the peak systolic wave, early diastolic wave, and end-diastolic wave produced by atrial contraction), is used to assess LV diastolic function. ${ }^{2}$ TDI can reveal 3 abnormal ventricular filling patterns: impaired relaxation (mild LVDD), pseudonormalization (moderate LVDD), and restrictive filling (severe LVDD). ${ }^{3}$ Moderate to severe LVDD can be present in $10 \%$ of patients with coronary artery occlusive disease who have neither systolic dysfunction nor history of congestive heart failure (CHF). The presence of moderate to severe LVDD predicts a 6-fold increased risk of $\mathrm{CHF}$ and a 4-fold increased risk of death from heart disease. ${ }^{4}$ LVDD occurs when ven- tricular filling is impaired either by abnormal relaxation or decreased compliance and is associated with significant morbidity and mortality. In cardiac surgery, especially after coronary artery bypass grafting (CABG), LVDD is a sensitive marker of myocardial ischemia and is associated with a poor prognosis after surgical myocardial revascularization. ${ }^{5}$ It is also predictive of adverse outcomes and death. ${ }^{3,6}$ Furthermore, some studies have shown that moderate to severe LVDD was an independent predictor of a worse late outcome after CABG. ${ }^{7,8}$ A recent prospective observational study clarified that severe LVDD is an independent predictor for respiratory complications and prolonged hospitalization after off-pump CABG (OPCAB). ${ }^{9}$ We hypothesized that aggravated LVDD will affect long-term prognosis after OPCAB. On the basis of this hypothesis, we wanted to identify the predictors of aggravated LVDD after OPCAB and to compare late outcomes according to whether LVDD had been aggravated postoperatively.

Received February 16, 2016; accepted July 4, 2016; released online July 29, 2016 Time for primary review: 21 days

Division of Thoracic and Cardiovascular Surgery, Severance Cardiovascular Hospital, Yonsei University Health System, Seoul (S.H.L., H.-C.J., K.-J.Y., Y.-N.Y.); Division of Thoracic and Cardiovascular Surgery, CHA Bundang Medical Center, CHA University, Seongnam-si, Gyeonggi-do (K.W.K.), Republic of Korea

The first two authors contributed equally to this work (S.H.L., K.W.K.).

Mailing address: Young-Nam Youn, MD, PhD, Severance Cardiovascular Hospital, Yonsei University Health System, 50-1 Yonsei-ro,

Seodaemun-gu, Seoul, Republic of Korea. E-mail: ynyoun@yuhs.ac

ISSN-1346-9843 doi:10.1253/circj.CJ-16-0165

All rights are reserved to the Japanese Circulation Society. For permissions, please e-mail: cj@j-circ.or.jp 


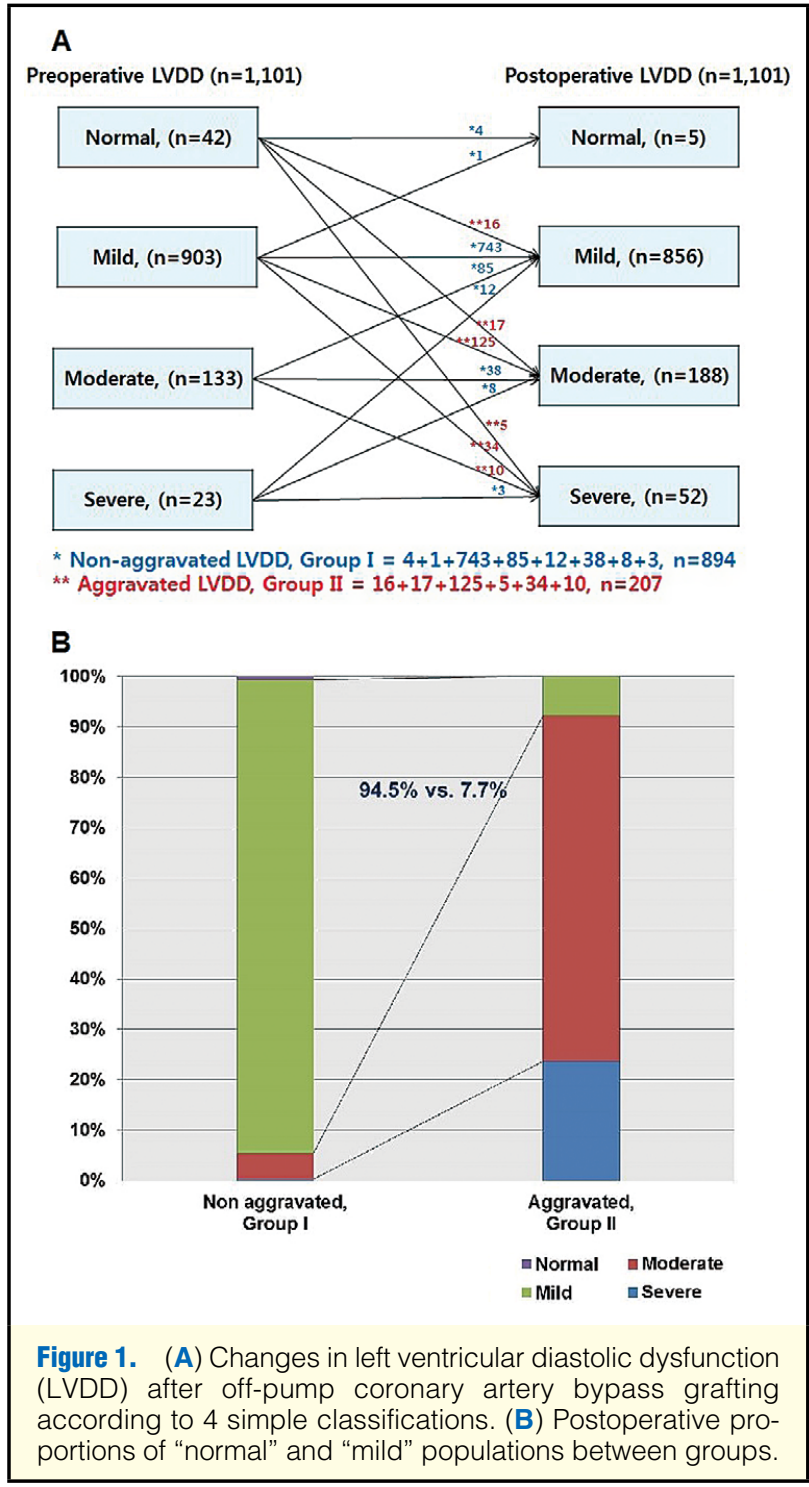

\section{Methods}

\section{Study Population}

Between January 2001 and December 2013, 2,583 patients underwent isolated OPCAB performed by 2 experienced surgeons (K.-J.Y. and Y.-N.Y.) at Severance Cardiovascular Hospital, Yonsei University College of Medicine. Among these patients, 1,254 who had postoperative echocardiography data available over the 6 months from the operation date were enrolled in this study. The latest echocardiography data from at least 6 months after the surgery were compared with preoperative echocardiography data. ${ }^{10} \mathrm{We}$ excluded 153 patients who had preoperative atrial fibrillation $(n=26)$, more than grade $2 / 4$ mitral regurgitation $(n=46)$, undetermined diastolic function including sinus tachycardia $(n=22)$, on-pump conversion $(n=7)$, minimal invasive direct CABG $(n=9)$, redo CABG $(n=11)$, perioperative myocardial infarction $(n=20)$, or an emergency operation $(n=12)$. The remaining 1,101 patients who underwent elective isolated OPCAB were enrolled in this study, which was approved by the Institutional Review Board of Yonsei University College of Medicine. Individual patient consent was waived because this study did not interfere with patient treatment, and the database was designed in such a way that individual patients could not be identified.

\section{Measurement of Diastolic Dysfunction}

Transthoracic echocardiography was performed pre- and postoperatively. Both 2D and Doppler echocardiography were performed with a commercially available echocardiographic unit equipped with an imaging transducer with both pulsedwave and tissue Doppler capability. From the apical window, the pulsed Doppler sample volume was placed at the mitral valve tips, and 5-10 cardiac cycles were recorded. From the mitral inflow velocities, the following variables were measured: peak velocity and time velocity integral of early (E) and late (A) filling of mitral inflow, and deceleration time (DT) of the E-wave velocity. TDI was used to measure mitral annular velocity $\left(\mathrm{E}^{\prime}\right)$ and late diastolic velocity of the mitral annulus $\left(\mathrm{A}^{\prime}\right)$. For TDI, the filter setting was lowered, and the Nyquist limit was adjusted (range, $15-20 \mathrm{~cm} / \mathrm{s}$ ). Gain was minimized for a clear tissue signal with minimal background noise. From the apical 4-chamber view, a 2- to 3-mm sample volume was placed at the septal corner of the mitral annulus. Measurements were recorded with simultaneous ECG (sweep speed, $50-100 \mathrm{~mm} / \mathrm{s}$ ). The mitral inflow filling pattern was also observed during the Valsalva maneuver to evaluate the effects of preload.

\section{Classification of LVDD and Changes in LVDD After Surgery}

Classification of LV diastolic function was defined prospectively based on mitral inflow pattern (m-mode), TDI, and age-adjusted values for all echo-Doppler parameters. Using the ratio of $E$ and $A$ velocities (E/A), $E^{\prime}$, and the ratio of $E$ and $E^{\prime}$ velocities $\left(E / E^{\prime}\right)$, patients were classified as having (1) normal diastolic function, (2) impaired relaxation (mild dysfunction), (3) pseudonormalization (moderate dysfunction), or 4) restrictive filling (severe dysfunction). The normal filling pattern was defined as $\mathrm{E} / \mathrm{A} \geq 1, \mathrm{E}^{\prime}>8 \mathrm{~cm} / \mathrm{s}$, and $\mathrm{E} / \mathrm{E}^{\prime}<10$; an impaired relaxation pattern was defined as $\mathrm{E} / \mathrm{A}<1$. To distinguish pseudonormal from normal diastolic function, 2 measures, E/A during a Valsalva maneuver and $\mathrm{E} / \mathrm{E}^{\prime}$, had to be abnormal; a pseudonormal filling pattern was defined as E/A of $0.75-1.5, \mathrm{E}^{\prime}<8 \mathrm{~cm} / \mathrm{s}$ or $\mathrm{E} / \mathrm{E}^{\prime}>10$; a restrictive filling pattern was defined as $\mathrm{E} / \mathrm{A}>1.5, \mathrm{E}^{\prime}<8 \mathrm{~cm} / \mathrm{s}$, or $\mathrm{E} / \mathrm{E}^{\prime}>10 .{ }^{11-16} \mathrm{We}$ defined a change in LVDD as a difference between preoperative and postoperative LVDD based on this classification. According to the change in LVDD, the patients were divided into 2 groups: (1) group I with non-aggravated LVDD and (2) group II with aggravated LVDD.

\section{Surgical Technique}

The operation was performed through a full sternotomy incision, and the left internal mammary artery was harvested in a semi-skeletonized fashion. The second choice for the graft was the radial artery, which was harvested with a Harmonic scalpel (Ethicon Endosurgery, Cincinnati, OH, USA). The right internal mammary artery, saphenous vein, or right gastroepiploic artery was also harvested if necessary. Systemic heparin $(0.7-1.0 \mathrm{mg} / \mathrm{kg})$ was administered to achieve a target activated clotting time $(\geq 300 \mathrm{~s})$ before ligation of the distal internal mammary artery. Target arteries were stabilized with a tissue stabilizer and heart positioner. During anastomosis, blood was removed from the arteriotomy sites with a misted carbon dioxide blower and irrigation with warm saline. After surgery, patients were transferred to the intensive care unit and managed as usual. 


\begin{tabular}{|c|c|c|c|c|}
\hline & Total & $\begin{array}{c}\text { Group I } \\
\text { (Non-aggravated, } \\
\mathrm{n}=894)\end{array}$ & $\begin{array}{c}\text { Group II } \\
\text { (Aggravated, } \\
\mathbf{n = 2 0 7 )}\end{array}$ & $P$ value \\
\hline Age (years) & $63.33 \pm 8.53$ & $63.71 \pm 8.31$ & $61.71 \pm 9.33$ & $<0.01$ \\
\hline$>65$ years & & $443(49.5)$ & $90(43.5)$ & 0.07 \\
\hline Female $(n, \%)$ & $280(25.4)$ & $228(25.5)$ & $52(25.1)$ & 0.91 \\
\hline Obesity $(\mathrm{n}, \%)\left(\mathrm{BMI}>30 \mathrm{~kg} / \mathrm{m}^{2}\right)$ & $38(3.5)$ & $29(3.2)$ & $9(4.3)$ & 0.43 \\
\hline HTN (n, \%) & $749(68.0)$ & $611(68.3)$ & $138(66.7)$ & 0.64 \\
\hline $\mathrm{DM}(\mathrm{n}, \%)$ & $446(40.5)$ & $363(40.6)$ & $83(40.1)$ & 0.89 \\
\hline PAOD (n, \%) & $120(10.9)$ & $90(10.1)$ & $30(14.5)$ & 0.07 \\
\hline CVA $(n, \%)$ & $116(10.5)$ & $96(10.7)$ & $20(9.7)$ & 0.65 \\
\hline COPD (n, \%) & $16(1.5)$ & $14(1.6)$ & $2(1.0)$ & 0.52 \\
\hline Renal failure $(\mathrm{n}, \%)\left(\mathrm{eGFR}<30 \mathrm{ml} / \mathrm{min} / 1.73 \mathrm{~m}^{2}\right)$ & $100(9.1)$ & $66(7.4)$ & $34(16.4)$ & $<0.01$ \\
\hline Smoking (n, \%) & $515(46.8)$ & $417(46.6)$ & $98(47.3)$ & 0.86 \\
\hline NYHA $(3,4: \mathrm{n}, \%)$ & $283(25.7)$ & $221(24.7)$ & $62(30.0)$ & 0.12 \\
\hline Myocardial infarction ( $\mathrm{n}, \%$ ) (<30 days) & $200(18.2)$ & $155(17.3)$ & $45(21.4)$ & 0.16 \\
\hline Unstable angina $(\mathrm{n}, \%)$ & $287(20.1)$ & $227(25.4)$ & $60(28.6)$ & 0.34 \\
\hline \multicolumn{5}{|l|}{ Medications (n, \%) } \\
\hline$\beta$-blocker & & $670(74.9)$ & $154(74.4)$ & 0.87 \\
\hline ACE inhibitor & & $256(28.6)$ & $61(29.5)$ & 0.81 \\
\hline ARB & & $174(19.5)$ & $43(20.8)$ & 0.67 \\
\hline Diuretics & & $153(17.1)$ & $39(18.5)$ & 0.56 \\
\hline Statin & & $394(44.1)$ & $88(42.5)$ & 0.68 \\
\hline
\end{tabular}

Data are presented as mean $\pm \mathrm{SD}$ or $\mathrm{n}(\%)$. ACE, angiotensin-converting enzyme; ARB, angiotensin II receptor blocker; BMI, body mass index; DM, diabetes mellitus; eGFR, estimated glomerular filtration rate; HTN, hypertension. Other abbreviations as in Table 1.

\section{Data Collection and Definition of Terms}

Patients' data were collected from the registry database, medical notes, and medical charts for later analysis. During follow-up, death and major adverse cardiac and cerebrovascular events (MACCE) were recorded. MACCE consisted of death or a cardiac event that was defined as a cardiac problem (heart failure, myocardial infarction, etc.) related readmission during the follow-up period and/or repeat revascularization by percutaneous intervention or bypass surgery, and cerebrovascular accident (CVA) that was confirmed by cerebral imaging study. Renal failure was defined as estimated glomerular filtration rate less than $30 \mathrm{ml} / \mathrm{min} / 1.73 \mathrm{~m}^{2}$ preoperatively, which was chronic kidney disease stage $4 / 5 .{ }^{17}$ The latest preoperative echocardiography data and the most recent postoperative echocardiography data that was obtained $\geq 6$ months after the operation and before the occurrence of MACCE were analyzed. Patient's echocardiography routine follow-up was performed just before discharge and at 6 and 12 months. After that, we routinely checked annually. If there were any cardiac symptoms during follow-up, echocardiography was performed regardless of the routine period.

\section{Study Endpoints}

The primary endpoint was aggravation of LVDD. The secondary endpoint was late mortality and morbidity such as MACCE related to LVDD aggravation postoperatively.

\section{Statistical Analysis}

Continuous variables were compared by paired t-test and are presented as mean \pm standard deviation (SD). The $\chi^{2}$ test was used for analysis of categorical variables. Variables significant in the univariate analysis $(\mathrm{P} \leq 0.2)$ were included in the multivariate model. Stepwise multivariate analysis was used to evaluate the independent variables for death and MACCE. To report the effect size of variables as predictors, odds ratios (OR) are expressed with $95 \%$ confidence intervals (CI) and P values. The model was evaluated using the Hosmer-Lemeshow goodness-of-fit test and residual analysis. To avoid multicollinearity among variants, a variance inflation factor (If VIF $>10$, there is something wrong with the analysis) was calculated. To investigate differences between groups in the cumulative event ratio for death and MACCE, the occurrence of death and MACCE is presented using Kaplan-Meier cumulative survival curves and compared using the log-rank test. Data were analyzed using SPSS for Windows, version 20.0 (SPSS Inc, Chicago, IL, USA). All P values $<0.05$ indicated a significant difference, and all $\mathrm{P}$ values were 2 -tailed.

\section{Results}

A total of 1,101 patients were enrolled. The mean follow-up was $7.10 \pm 3.39$ years. According to the preoperative severity of LVDD, the patients were classified into 4 groups: normal $(n=42,3.8 \%)$, mild $(n=903,82.0 \%)$, moderate $(n=133,12.1 \%)$, or severe ( $n=23,2.1 \%)$ LVDD. According to the postoperative severity of LVDD, patients in each group was reclassified into 4 groups as for the preoperative classification: normal $(n=5$, $0.5 \%)$, mild $(\mathrm{n}=856,77.7 \%)$, moderate $(\mathrm{n}=188,17.1 \%)$, or severe $(n=52,4.7 \%)$ LVDD. After this classification, nonaggravated LVDD was defined as improved LVDD or no change in LVDD postoperatively, and aggravated LVDD was defined as aggravated LVDD postoperatively. The changes in LVDD according to the 4 simple classifications are summarized in Figure 1A and the postoperative proportions of "normal" and "mild" populations between groups are shown in Figure 1B.

As a result, all 1,101 patients were grouped according to the change in the severity of LVDD after OPCAB: group I with 


\begin{tabular}{|c|c|c|c|}
\hline & $\begin{array}{c}\text { Group I } \\
\text { (Non-aggravated, } \\
n=894)\end{array}$ & $\begin{array}{c}\text { Group II } \\
\text { (Aggravated, } \\
\mathbf{n = 2 0 7 )}\end{array}$ & $P$ value \\
\hline \multicolumn{4}{|l|}{ LVEF (\%) } \\
\hline Preoperative & $56.61 \pm 13.99$ & $57.00 \pm 13.72$ & 0.72 \\
\hline Postoperative & $58.33 \pm 11.58$ & $56.36 \pm 13.24$ & 0.05 \\
\hline \multicolumn{4}{|l|}{ LVEDD (mm) } \\
\hline Preoperative & $51.17 \pm 6.03$ & $51.34 \pm 5.39$ & 0.71 \\
\hline Postoperative & $49.54 \pm 5.86$ & $51.59 \pm 6.36$ & $<0.01$ \\
\hline \multicolumn{4}{|l|}{ LVESD (mm) } \\
\hline Preoperative & $35.74 \pm 7.63$ & $35.66 \pm 6.67$ & 0.89 \\
\hline Postoperative & $34.28 \pm 6.87$ & $36.34 \pm 7.64$ & $<0.01$ \\
\hline \multicolumn{4}{|l|}{ LA diameter (mm) } \\
\hline Preoperative & $39.29 \pm 5.15$ & $39.66 \pm 5.33$ & 0.36 \\
\hline Postoperative & $40.26 \pm 5.31$ & $43.51 \pm 6.55$ & $<0.01$ \\
\hline \multicolumn{4}{|l|}{ E velocity (m/s) } \\
\hline Preoperative & $0.72 \pm 0.45$ & $0.87 \pm 0.34$ & $<0.01$ \\
\hline Postoperative & $0.62 \pm 0.49$ & $0.95 \pm 0.23$ & $<0.01$ \\
\hline \multicolumn{4}{|l|}{ A velocity (m/s) } \\
\hline Preoperative & $0.93 \pm 0.25$ & $0.89 \pm 0.33$ & 0.12 \\
\hline Postoperative & $0.94 \pm 0.24$ & $0.75 \pm 0.45$ & $<0.01$ \\
\hline \multicolumn{4}{|l|}{$E / A$} \\
\hline Preoperative & $0.87 \pm 0.50$ & $0.92 \pm 0.33$ & 0.27 \\
\hline Postoperative & $0.78 \pm 0.26$ & $1.42 \pm 0.66$ & $<0.01$ \\
\hline \multicolumn{4}{|c|}{ Deceleration time of $E$ wave (ms) } \\
\hline Preoperative & $212.15 \pm 47.30$ & $205.88 \pm 45.95$ & 0.12 \\
\hline Postoperative & $225.77 \pm 46.80$ & $185.35 \pm 44.78$ & $<0.01$ \\
\hline \multicolumn{4}{|l|}{$E^{\prime}$ velocity $(\mathrm{cm} / \mathrm{s})$} \\
\hline Preoperative & $4.90 \pm 1.59$ & $5.46 \pm 1.91$ & $<0.01$ \\
\hline Postoperative & $5.03 \pm 1.47$ & $5.26 \pm 1.51$ & 0.05 \\
\hline \multicolumn{4}{|l|}{$A^{\prime}$ velocity $(\mathrm{cm} / \mathrm{s})$} \\
\hline Preoperative & $8.25 \pm 1.87$ & $7.93 \pm 1.75$ & 0.57 \\
\hline Postoperative & $8.54 \pm 1.83$ & $7.56 \pm 2.14$ & $<0.01$ \\
\hline \multicolumn{4}{|l|}{$E / E^{\prime}$} \\
\hline Preoperative & $13.80 \pm 5.93$ & $13.12 \pm 5.07$ & 0.19 \\
\hline Postoperative & $12.32 \pm 5.20$ & $18.23 \pm 9.31$ & $<0.01$ \\
\hline
\end{tabular}

Data are presented as mean $\pm S D$. $E$, peak velocity of early diastolic filling of mitral inflow; $E^{\prime}$, peak early diastolic velocity of the mitral annulus; $E / A$, ratio of $E$ and $A$ velocities; $E F$, ejection fraction. Other abbreviations as in Table 1.

non-aggravated LVDD $(\mathrm{n}=894)$ and group II with aggravated LVDD ( $\mathrm{n}=207)$. The baseline demographics and clinical characteristics in patients were similar except for age and preoperative renal failure (Table 1 ).

The mean age of group I patients was higher than that of group II $(63.71 \pm 8.31$ vs. $61.71 \pm 9.33$ years, $\mathrm{P}<0.01)$. The prevalence of renal failure was higher in group II (7.4\% vs. $16.4 \%, \mathrm{P}<0.01)$. The mean follow-up interval between echocardiography testing was $4.28 \pm 3.05$ years. Preoperative and postoperative follow-up echocardiography data are shown in Table 2. Preoperative E velocity, $\mathrm{E}^{\prime}$ velocity, and postoperative LV end-diastolic diameter (LVEDD), LV end-systolic diameter (LVESD), left atrial (LA) diameter, E velocity, E/A, $\mathrm{E}^{\prime}$ velocity, and $\mathrm{E} / \mathrm{E}^{\prime}$ were significantly higher in group II. Postoperative LVEF, A velocity, DT of the E wave, and $\mathrm{A}^{\prime}$ velocity were significantly higher in group I. Table 3 shows the mean number of anastomoses, use of 1 or 2 internal thoracic arteries, incomplete revascularization, operation time, and length of hospital stay with no significant differences between groups I and II. However, the total arterial grafting rate was significantly lower in group II (62.3\% vs. $52.7 \%$, $\mathrm{P}=0.01)$. MACCE incidence in the aggravated LVDD group $(\mathrm{n}=57,27.5 \%)$ was significantly higher compared with the non-aggravated LVDD group $(n=142,15.9 \%)$ (Table 4).

Univariate and multivariate logistic regression analyses were conducted to identify independent predictors of aggravated LVDD (Table 5). Peripheral artery obstructive disease (PAOD) (OR 1.60, 95\% CI: 1.02-2.52, $\mathrm{P}=0.04$ ), and preoperative renal failure (OR 2.47, 95\% CI: 1.55-3.94, $\mathrm{P}<0.01$ ) anticipated aggravated LVDD. Among the preoperative echocardiography data, preoperative $\mathrm{A}^{\prime}$ velocity (OR $0.85,95 \%$ CI: $0.76-0.95, \mathrm{P}<0.01)$ inversely correlated with aggravated LVDD. The Cox proportional hazards model was used to analyze the independent predictors of MACCE and overall survival by entering all variables. Aggravated LVDD (hazard ratio [HR] $1.83,95 \% \mathrm{CI}: 1.35-2.49, \mathrm{P}<0.01$ ), postoperative LVDD ( $\mathrm{P}<0.01)$, age (HR 1.04, 95\% CI: 1.03-1.06, $\mathrm{P}<0.01)$, diabetes mellitus (HR 1.38, 95\% CI: 1.04-1.83, $\mathrm{P}=0.03$ ), PAOD 
Table 3. Operative and Postoperative Data of Patients With LV Diastolic Dysfunction

\begin{tabular}{lccc} 
& $\begin{array}{c}\text { Group I } \\
\text { (Non-aggravated, } \\
\mathbf{n = 8 9 4 )}\end{array}$ & $\begin{array}{c}\text { Group II } \\
\text { (Aggravated, } \\
\mathbf{n = 2 0 7} \text { ) }\end{array}$ & P value \\
Anastomoses per patient $(\mathrm{n})$ & $3.2 \pm 0.8$ & $3.1 \pm 0.8$ & 0.31 \\
Total arterial grafting (n, \%) & $557(62.3)$ & $109(52.7)$ & 0.01 \\
Use of internal thoracic artery (n, \%) & $890(99.6)$ & $206(99.5)$ & 0.95 \\
Aortocoronary bypass (n, \%) & $240(26.8)$ & $66(31.9)$ & 0.15 \\
Incomplete revascularization (n, \%) & $76(8.5)$ & $24(11.6)$ & 0.16 \\
Operation time, min & $245.6 \pm 46.0$ & $243.9 \pm 43.8$ & 0.62 \\
Hospital stay, days & $12.6 \pm 10.1$ & $13.1 \pm 7.8$ & 0.54 \\
\hline
\end{tabular}

Data presented as mean \pm SD, $\mathrm{n}(\%)$. Abbreviation as in Table 1 .

\begin{tabular}{|c|c|c|c|}
\hline & $\begin{array}{c}\text { Group I } \\
\text { (Non-aggravated, } \\
\mathbf{n = 8 9 4 )}\end{array}$ & $\begin{array}{c}\text { Group II } \\
\text { (Aggravated, } \\
\mathbf{n = 2 0 7 )}\end{array}$ & $P$ value \\
\hline MACCE $(n, \%)$ & $142(15.9)$ & $57(27.5)$ & $<0.01$ \\
\hline Death & $67(7.5)$ & $38(18.4)$ & $<0.01$ \\
\hline Cardiac event & $63(7.0)$ & $21(10.1)$ & 0.13 \\
\hline Cerebrovascular accident & $22(2.5)$ & $6(2.9)$ & 0.72 \\
\hline
\end{tabular}

Cardiac event=cardiac-related readmission (heart failure, myocardial infarction, etc) and/or repeat revascularization. MACCE, major adverse cardiac and cerebrovascular events. Other abbreviations as in Table 1.

\begin{tabular}{|c|c|c|c|c|c|}
\hline \multirow[b]{3}{*}{ Risk factors } & \multicolumn{3}{|c|}{ Univariate } & \multicolumn{2}{|c|}{ Multivariate } \\
\hline & OR $(95 \% \mathrm{Cl})$ & VIF & $P$ value & OR $(95 \% \mathrm{Cl})$ & $P$ value \\
\hline & & & & & \\
\hline \multirow{2}{*}{$\begin{array}{l}\text { Age } \\
>65 \text { years }\end{array}$} & $0.97(0.96-0.99)$ & 1.048 & $<0.01$ & $0.97(0.95-0.98)$ & $<0.01$ \\
\hline & $0.98(0.93-1.05)$ & & 0.63 & & \\
\hline PAOD & $1.51(0.97-2.36)$ & 1.011 & 0.07 & $1.60(1.02-2.52)$ & 0.04 \\
\hline Renal failure & $2.47(1.58-3.85)$ & 1.070 & $<0.01$ & $2.47(1.55-3.94)$ & $<0.01$ \\
\hline NYHA class $\geq 3$ & $1.30(0.93-1.82)$ & 1.077 & 0.12 & - & - \\
\hline Myocardial infarction ( $<30$ days) & $1.22(0.79-1.89)$ & 1.061 & 0.37 & - & - \\
\hline Total arterial grafting & $0.29(0.50-0.91)$ & 1.663 & $<0.01$ & $0.72(0.52-0.99)$ & 0.04 \\
\hline Aortocoronary bypass & $1.28(1.92-1.77)$ & 1.604 & 0.15 & - & - \\
\hline Incomplete revascularization & $1.07(0.71-1.61)$ & 1.011 & 0.76 & - & - \\
\hline \multicolumn{6}{|l|}{ Echocardiography parameters } \\
\hline Preoperative LVEDD & $1.01(0.98-1.03)$ & 6.301 & 0.71 & - & - \\
\hline Preoperative LVESD & $1.00(0.98-1.02)$ & 6.707 & 0.89 & - & - \\
\hline Preoperative A velocity & $0.60(0.34-1.06)$ & 1.248 & 0.08 & - & - \\
\hline Preoperative $A^{\prime}$ velocity & $0.91(0.83-1.00)$ & 1.512 & 0.06 & $0.85(0.76-0.95)$ & $<0.01$ \\
\hline Preoperative $E / E^{\prime}$ & $0.98(0.95-1.01)$ & 1.666 & 0.19 & - & - \\
\hline
\end{tabular}

$A$, late diastolic filling due to atrial contraction; $\mathrm{A}^{\prime}$, late diastolic velocity of the mitral annulus; $\mathrm{Cl}$, confidence interval; $E / E^{\prime}$, ratio of $E$ and $E^{\prime}$ velocities; $E D D$, end-diastolic dimension; $E S D$, end-systolic dimension; LV, left ventricular; NYHA, New York Heart Association; OR, odds ratio; PAOD, peripheral artery obstructive disease; VIF, variance inflation factor.

(HR 1.64, 95\% CI: 1.17-2.72, P=0.01), renal failure (HR 1.78, 95\% CI: $1.17-2.72, \mathrm{P}=0.01)$, and New York Heart Association (NYHA) classification $\geq 3$ (HR 1.37, 95\% CI: 1.03-1.84, $\mathrm{P}=0.03)$ were significantly associated with MACCE. Aggravated LVDD (HR 2.26, 95\% CI: 1.51-3.38, P<0.01), postoperative LVDD $(\mathrm{P}<0.01)$, age (HR 1.09, 95\% CI: 1.06-1.12, $\mathrm{P}<0.01$ ), diabetes mellitus (HR 1.60, 95\% CI: 1.07-2.40,
$\mathrm{P}=0.02$ ), $\mathrm{PAOD}$ (HR 2.58, 95\% CI: 1.68-3.40, $\mathrm{P}<0.01$ ), renal failure (HR 2.98, 95\% CI: $1.80-4.94, \mathrm{P}<0.01$ ), and NYHA classification $\geq 3$ (HR 1.59, 95\% CI: $1.07-2.47, \mathrm{P}=0.02$ ) were significantly related to overall survival (Table 6).

Kaplan-Meier survival curves showed that aggravated LVDD was significantly associated with MACCE and overall survival. The respective 2-, 6-, and 10-year results of freedom 


\begin{tabular}{|c|c|c|c|c|}
\hline & \multicolumn{2}{|c|}{ MACCE } & \multicolumn{2}{|c|}{ Overall survival } \\
\hline & HR (95\% Cl) & $P$ value & HR (95\% Cl) & $P$ value \\
\hline Aggravated LVDD & $1.75(1.28-2.38)$ & $<0.01$ & $2.30(1.54-3.44)$ & $<0.01$ \\
\hline Postoperative LVDD & & $<0.01$ & & $<0.01$ \\
\hline Mild (2) vs. Normal (1) & & 0.96 & & 0.95 \\
\hline Moderate (3) vs. Normal (1) & $0.46(0.30-0.72)$ & $<0.01$ & $0.32(0.19-0.54)$ & $<0.01$ \\
\hline Severe (4) vs. Normal (1) & $0.58(0.34-0.99)$ & 0.05 & $0.41(0.21-0.81)$ & 0.01 \\
\hline Age & $1.04(1.02-1.06)$ & $<0.01$ & $1.09(1.06-1.12)$ & $<0.01$ \\
\hline DM & $1.36(1.02-1.81)$ & 0.04 & $1.61(1.08-2.40)$ & 0.02 \\
\hline PAOD & $1.74(1.23-2.45)$ & $<0.01$ & $2.47(1.61-3.79)$ & $<0.01$ \\
\hline Renal failure & $1.84(1.19-2.82)$ & 0.01 & $3.08(1.86-5.09)$ & $<0.01$ \\
\hline Family history of CAOD & $1.76(1.00-3.10)$ & 0.05 & $2.20(0.89-5.41)$ & 0.09 \\
\hline NYHA $(3,4)$ & $1.33(0.99-1.79)$ & 0.06 & $1.56(1.04-2.32)$ & 0.03 \\
\hline Incomplete revascularization & $1.50(1.01-2.25)$ & 0.05 & $1.73(1.04-2.91)$ & 0.04 \\
\hline
\end{tabular}

CAOD, coronary artery obstructive disease; HR, hazards ratio. Other abbreviations as in Tables 1,2,5.

from MACCE in group I vs. group II were $96.0 \%$ vs. $94.2 \%$, $88.0 \%$ vs. $79.4 \%$, and $77.4 \%$ vs. $63.8 \%$ (log-rank $\mathrm{P}=0.01$ ) (Figure 2A). The respective 2-, 6-, and 10-year results of overall survival in group I vs. group II were $98.3 \%$ vs. $96.6 \%$, $94.4 \%$ vs. $87.0 \%$, and $87.7 \%$ vs. $75.9 \%$ (log-rank $\mathrm{P}<0.01$ ) (Figure 2B). However, aggravated LVDD was not significantly related to cardiac events or CVA (Figures 2C,D).

\section{Discussion}

In the present study, we sought to investigate preoperative predictors of aggravated LVDD and the clinical impact of aggravated LVDD after OPCAB. Liu and co-workers ${ }^{8}$ compared long-term survival after $\mathrm{CABG}$ according to the postoperative filling pattern. During more than 60 months of follow-up, the patients with moderate LVDD (pseudonormal) or severe LVDD (restrictive filling) had a poorer long-term survival compared with those with normal LV function or mild LVDD (impaired relaxation) after CABG. Also, they clarified the DT of the $\mathrm{E}$ wave as a predictive factor for cardiac events. In this respect, there are some questions about the benefit of $\mathrm{CABG}$ for patients with severe LVDD. Vaskelyte and associates ${ }^{18}$ investigated patients with severe LV systolic dysfunction (EF $<35 \%$ ) and severe LVDD (restrictive filling) who were undergoing CABG. They concluded that severe LVDD correlated with high frequency of early mortality, morbidity, and minimal improvement in LV systolic function, but they did not include patients with normal diastolic function. LVDD can be defined as the inability of the LV chamber to adequately fill at low atrial pressures unrelated to intrinsic valve disease or pericardial pathology; this dysfunction can result from impaired LV compliance (passive mechanism) or from an alteration in LV relaxation (active mechanism). In ischemic heart disease, impairment of LV diastolic function precedes systolic dysfunction. So LVDD might be an important predictive factor for upcoming systolic dysfunction. Youn and colleagues ${ }^{9}$ found that preoperative LVDD increased postoperative respiratory complications and hospital stay over 12 days. They suspected these phenomena were associated with circulating volume overload during intraoperative and postoperative periods in LVDD after OPCAB.

These studies focused on LVDD itself, but poor LVDD that already exists might be an uncorrectable factor regardless of coronary revascularization. So we previously analyzed clinical results according to pre- and postoperative LVDD (Figure S1). In that analysis, preoperative LVDD did not affect late results, but postoperative LVDD showed significant clinical correlation with late outcomes, based on which we assumed the results came from the effects of OPCAB. This was the main reason why we intend to focus on the change in LVDD after revascularization. Changes in diastolic function maybe strongly related to coronary flow patency after coronary bypass, so we hypothesized that the change might be a more sensitive predictive factor for late clinical outcomes after OPCAB. Therefore, in the present study we aimed to confirm the hypothesis that aggravated LVDD will affect long-term prognosis and to clarify the predictors of LVDD after OPCAB. Our major findings can be summarized as follows.

First, preoperative renal failure was frequent and the total arterial grafting rate was significantly lower in patients with aggravated LVDD. LVDD was related to several conditions that increase postoperative risk, such as old age, diabetes, low $\mathrm{EF}$, and renal failure. In particular, the association of LVDD with death from heart disease was likely caused by the interim development of heart failure. A potential explanation for this association is that the greater LV size results in a lower EF, more inducible ischemia, and lower creatinine clearance. ${ }^{4}$ Minakata et al also found that advanced preoperative renal failure is a strong predictor of postoperative outcomes after CABG. ${ }^{19}$ Our study clarified a direct correlation between lower renal function and aggravated LVDD.

The mean age at operation of group I was higher than that of group II $(63.71 \pm 8.31$ vs. $61.71 \pm 9.33$ years, $\mathrm{P}<0.01)$, but there was no significant difference in the number of patients aged over 65 years $(49.6 \%$ vs. $43.5 \%, \mathrm{P}=0.12)$. In our results, age was negatively related to aggravated LVDD (OR 0.97); in fact, the OR was nearly 1.0, which means equivalent influence to LVDD. We re-analyzed the old age ( $\geq 65$ years) effect as a variant for LVDD, but it was not significant as a risk factor (Table 5). Positively related effect of age on MACCE and overall survival rate was natural course considering all-cause mortality definition. In our series, age was also an independent predictor of MACCE and overall survival by Cox proportional hazards analysis. But some reports take the opposite view on the age effect; Ohira et al suggest that age at operation had no effect on long-term cardiac outcomes in patients undergoing 

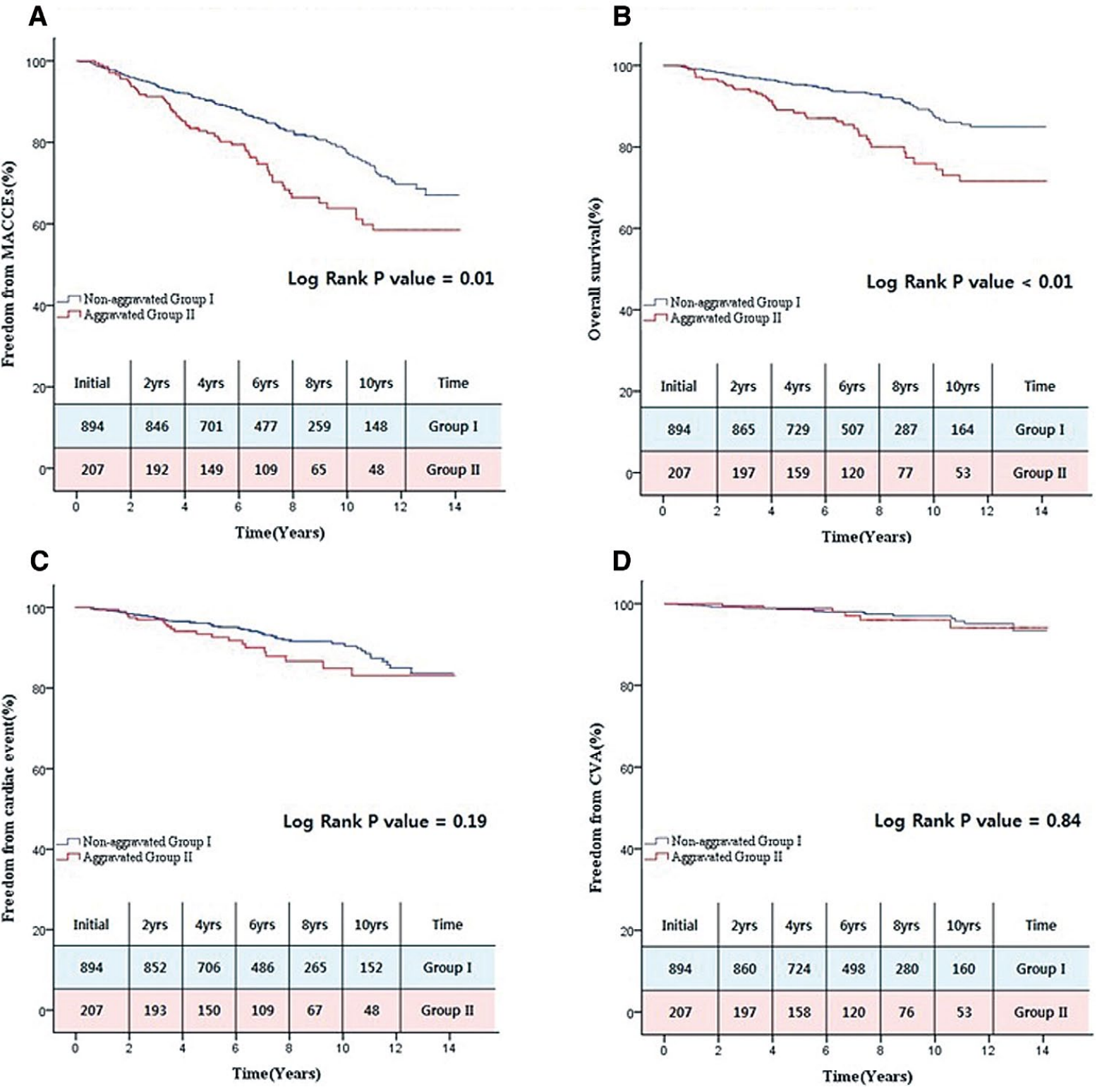

Figure 2. Comparison of major adverse cardiac and cerebrovascular events (MACCE) and overall survival rate using KaplanMeier method. (A) MACCE; (B) overall survival; (C) cardiac event; (D) cerebrovascular accident.

OPCAB. ${ }^{20}$ In addition, the total arterial grafting rate was significantly lower in the present patients with aggravated LVDD. In this study, almost all of the operations (99.5\%) were performed using the internal thoracic artery as a graft, and the majority of total arterial grafting operations were arterial composite grafting ( $\mathrm{Y}$ anastomosis using the radial artery, internal thoracic artery, or gastroepiploic artery as a free graft) with sequential bypass. Some studies suggest superior outcomes with respect to long-term death after $\mathrm{CABG}$ in patients undergoing total arterial grafting compared with patients undergoing surgery using a mixed use of internal thoracic artery and vein graft. ${ }^{21}$ Arterial composite grafting with sequential coronary artery bypass is a feasible and effective method for multivessel myocardial revascularization. ${ }^{22}$ However, other studies suggest that mid- and long-term results of total arterial grafting patients are quite similar in mixed arterial and venous graft patients. ${ }^{23,24}$ This is still an important and heavily debated issue. From our results, we surmised that total arterial grafting had positive effects on LV diastolic function, which might be related to long-term outcomes after OPCAB. Unfortunately, LVDD was aggravated even after revascularization in group II. After revascularization, if there is no improvement in LVDD and regional wall motion, it might be highly associated with pre-existing myocardial irreversible damage. The most promising technique for predicting myocardial function is MIBI scan or dobutamine stress echocardiography, but using these modalities for routine screening of every preoperative patient is not practical in the real world. So at the least patients with 
preoperative LVDD should be checked, as mentioned. Another important cause of fruitless results may be complete revascularization or not. In this study the average number of anastomosis was 3.2 and we performed complete revascularization in over $90 \%$, so we do not consider this technical factor as important in our series. Also, there is another limitation of the evaluation technique for LVDD, because although traditionally transmitral Doppler echocardiography is used to assess LVDD, it can sometimes be missed by this method compared with the more recent TDI.

Second, in our multivariate logistic regression analysis, preoperative extracardiac arteriopathy, renal failure, and $\mathrm{A}^{\prime}$ velocity in the echocardiographic data independently predicted aggravated LVDD. Preoperative PAOD and renal failure were related to a high risk for severe atherosclerotic disease and high rates of comorbidities. ${ }^{25}$ These factors might have contributed to aggravated LVDD. Interestingly, the mitral valve $A^{\prime}$ velocity in the preoperative echocardiography data was the only parameter to predict aggravation of LVDD. The $\mathrm{A}^{\prime}$ velocity, which is a measure of intrinsic atrial longitudinal contraction by TDI, is a preload independent marker of atrial contractile function and is inversely correlated to atrial volume. ${ }^{26}$ Furthermore, more advanced LVDD (greater decrease in LV compliance) was characterized by increased pressure for a given volume. The increased filling pressure influences the LV inflow pattern, which will change first to pseudonormal and later to restrictive. ${ }^{27}$ The comparison of preoperative and postoperative echocardiography data in our study showed that decreased postoperative LV function and compliance (lower LVEF and greater LVEDD, LVESD, and LA diameter) were significantly worse in patients with aggravated LVDD.

Third, in the Cox proportional hazards analysis, aggravated LVDD was related to higher rates of long-term MACCE and poor overall survival, and the Kaplan-Meier survival curves showed that aggravated LVDD was associated with a high risk of MACCE and poor overall survival rates (Figure S2). Pinamonti et $\mathrm{al}^{28}$ evaluated the mortality rate in dilated cardiomyopathy patients and found the highest rate in patients with persistent restrictive filling (severe LVDD). However, the mortality rate in patients with reversible restrictive filling was similar to patients with nonrestrictive filling. In this respect, we assume that an improvement in LVDD, or at least not aggravated LVDD, is related to better outcomes after OPCAB.

\section{Study Limitations}

First, the follow-up intervals between echocardiography testing were irregular. After OPCAB, the severity of LVDD might change during the follow-up periods. Usually, ventricular diastolic filling is impaired early after $\mathrm{CABG}$, but improves approximately 6 months later. ${ }^{10}$ To minimize this confounding factor, all of the postoperative echocardiography data in our study was from at least 6 months after the operation and before the occurrence of MACCE. Second, the patients with severe LVDD who still had severe LVDD postoperatively were classified in the non-aggravated group (group I). As mentioned earlier, these patients might have the poorest outcomes among all patients and might be a confounding factor in our results. However, there were only 3 of these patients and thus may have had little effect on statistical significance. The third is that unfortunately we could not check myocardial viability in all cases using MIBI scan or SPECT, so we just checked wall motion abnormality using echocardiography. From this limited evaluation, we could not correct for pre-existing uncorrectable myocardial dysfunction. The last, our coronary patency evaluation protocol is angio-CT just before discharge and follow-up CT evaluation is usually done at postoperatively 1 year. After that, if patients suffer from chest pain, additional CT angiography is scheduled for detecting bypass graft patency. However, we could not collect complete follow-up data from our study population. So, the correlation between graft patency and LVDD could be a type of limitation of this study and further study is warranted.

\section{Conclusions}

Our findings suggest that PAOD, preoperative renal failure, and preoperative $\mathrm{A}^{\prime}$ velocity might be independent predictors for aggravated LVDD after OPCAB. Furthermore, aggravated LVDD after OPCAB is poor prognostic factor for MACCE and overall survival.

\section{References}

1. Aurigemma GP, Gaasch WH. Clinical practice: Diastolic heart failure. N Engl J Med 2004; 351: $1097-1105$.

2. Dokainish H. Tissue Doppler imaging in the evaluation of left ventricular diastolic function. Curr Opin Cardiol 2004; 19: 437-441.

3. Djaiani GN, McCreath BJ, Ti LK, Mackensen BG, Podgoreanu M, Phillips-Bute B, et al. Mitral flow propagation velocity identifies patients with abnormal diastolic function during coronary artery bypass graft surgery. Anesth Analg 2002; 95: 524-530, table of contents.

4. Ren X, Ristow B, Na B, Ali S, Schiller NB, Whooley MA. Prevalence and prognosis of asymptomatic left ventricular diastolic dysfunction in ambulatory patients with coronary heart disease. Am J Cardiol 2007; 99: 1643-1647.

5. van der Maaten JM, de Vries AJ, Henning RH, Epema AH, van den Berg MP, Lip H. Effects of preoperative treatment with diltiazem on diastolic ventricular function after coronary artery bypass graft surgery. J Cardiothorac Vasc Anesth 2001; 15: 710-716.

6. Paulus WJ, Tschope C, Sanderson JE, Rusconi C, Flachskampf FA, Rademakers FE, et al. How to diagnose diastolic heart failure: A consensus statement on the diagnosis of heart failure with normal left ventricular ejection fraction by the Heart Failure and Echocardiography Associations of the European Society of Cardiology. Eur Heart J 2007; 28: 2539-2550.

7. Merello L, Riesle E, Alburquerque J, Torres H, Aranguiz-Santander E, Pedemonte O, et al. Risk scores do not predict high mortality after coronary artery bypass surgery in the presence of diastolic dysfunction. Ann Thorac Surg 2008; 85: 1247-1255.

8. Liu J, Tanaka N, Murata K, Ueda K, Wada Y, Oyama R, et al. Prognostic value of pseudonormal and restrictive filling patterns on left ventricular remodeling and cardiac events after coronary artery bypass grafting. Am J Cardiol 2003; 91: 550-554.

9. Youn YN, Shim CY, Yang H, Hong S, Chung N, Yoo KJ. Effect of diastolic dysfunction on early outcomes during elective off-pump coronary artery bypass grafting: A prospective observational study. Ann Thorac Surg 2011; 92: 587-593.

10. Shi Y, Denault AY, Couture P, Butnaru A, Carrier M, Tardif JC. Biventricular diastolic filling patterns after coronary artery bypass graft surgery. J Thorac Cardiovasc Surg 2006; 131: 1080-1086.

11. Ommen SR. Echocardiographic assessment of diastolic function. Curr Opin Cardiol 2001; 16: 240-245.

12. Oh BK, Kim YJ, Park YN, Choi J, Kim KS, Park C. Quantitative assessment of hTERT mRNA expression in dysplastic nodules of HBV-related hepatocarcinogenesis. Am J Gastroenterol 2006; 101: $831-838$.

13. De Boeck BW, Cramer MJ, Oh JK, van der Aa RP, Jaarsma W. Spectral pulsed tissue Doppler imaging in diastole: A tool to increase our insight in and assessment of diastolic relaxation of the left ventricle. Am Heart J 2003; 146: 411-419.

14. Persson H, Lonn E, Edner M, Baruch L, Lang CC, Morton JJ, et al; Investigators of the CHARM Echocardiographic Substudy. Diastolic dysfunction in heart failure with preserved systolic function: Need for objective evidence: Results from the CHARM Echocardiographic Substudy-CHARMES. J Am Coll Cardiol 2007; 49: 687-694.

15. Gilman G, Nelson TA, Hansen WH, Khandheria BK, Ommen SR. Diastolic function: A sonographer's approach to the essential echocardiographic measurements of left ventricular diastolic function. $J$ Am Soc Echocardiogr 2007; 20: 199-209.

16. Khouri SJ, Maly GT, Suh DD, Walsh TE. A practical approach to the echocardiographic evaluation of diastolic function. J Am Soc Echocardiogr 2004; 17: 290-297. 
17. Go AS, Chertow GM, Fan D, McCulloch CE, Hsu CY. Chronic kidney disease and the risks of death, cardiovascular events, and hospitalization. N Engl J Med 2004; 351: 1296-1305.

18. Vaskelyte J, Stoskute N, Kinduris S, Ereminiene E. Coronary artery bypass grafting in patients with severe left ventricular dysfunction: Predictive significance of left ventricular diastolic filling pattern. Eur J Echocardiogr 2001; 2: 62-67.

19. Minakata K, Bando K, Tanaka S, Takanashi S, Konishi H, Miyamoto $\mathrm{Y}$, et al. Preoperative chronic kidney disease as a strong predictor of postoperative infection and mortality after coronary artery bypass grafting. Circ J 2014; 78: 2225-2231.

20. Ohira S, Doi K, Numata S, Yamazaki S, Yamamoto T, Fukuishi M, et al. Does age at operation influence the short- and long-term outcomes of off-pump coronary artery bypass grafting? Circ J 2015; 79: $2177-2185$

21. Zacharias A, Schwann TA, Riordan CJ, Durham SJ, Shah AS, Habib $\mathrm{RH}$. Late results of conventional versus all-arterial revascularization based on internal thoracic and radial artery grafting. Ann Thorac Surg 2009; 87: 19-26 e2.

22. Fukui T, Takanashi S, Hosoda Y, Suehiro S. Total arterial myocardial revascularization using composite and sequential grafting with the off-pump technique. Ann Thorac Surg 2005; 80: 579-585.

23. Baskett RJ, Cafferty FH, Powell SJ, Kinsman R, Keogh BE, Nashef SA. Total arterial revascularization is safe: Multicenter ten-year analysis of 71,470 coronary procedures. Ann Thorac Surg 2006; 81: $1243-1248$.

24. Garatti A, Castelvecchio S, Canziani A, Corain L, Generali T, Mossuto E, et al. Long-term results of sequential vein coronary artery bypass grafting compared with totally arterial myocardial revascularization: A propensity score-matched follow-up studydagger. Eur J Cardiothorac Surg 2014; 46: 1006-1013; discussion 1013.

25. Gatti G, Maschietto L, Dell'Angela L, Benussi B, Forti G, Dreas L, et al. Predictors of immediate and long-term outcomes of coronary bypass surgery in patients with left ventricular dysfunction. Heart Vessels 2016; 31: 1045-1055.

26. Thomas L, Boyd A, Thomas SP, Schiller NB, Ross DL. Atrial structural remodelling and restoration of atrial contraction after linear ablation for atrial fibrillation. Eur Heart J 2003; 24: 1942-1951.

27. Lindstrom L, Wranne B. Pulsed tissue Doppler evaluation of mitral annulus motion: A new window to assessment of diastolic function. Clin Physiol 1999; 19: 1-10.

28. Pinamonti B, Zecchin M, Di Lenarda A, Gregori D, Sinagra G, Camerini F. Persistence of restrictive left ventricular filling pattern in dilated cardiomyopathy: An ominous prognostic sign. J Am Coll Cardiol 1997; 29: 604-612.

\section{Supplementary Files}

Supplementary File 1

Figure S1. Comparison of clinical results according to 4 simple classifications of preoperative left ventricular diastolic dysfunction (LVDD)

Figure S2. Comparisons among 3 groups (Improved, No change, Aggravated) using Kaplan Meir method.

Please find supplementary file(s);

http://dx.doi.org/10.1253/circj.CJ-16-0165 